\title{
Hospital based initiative to decrease readmission rates in end-stage liver disease
}

\author{
Sheela S. Reddy ${ }^{1}$, Amy Javia $^{2}$ and Dina Halegoua-DeMarzio ${ }^{1 *}$ \\ ${ }^{1}$ Division of Gastroenterology and Hepatology, Thomas Jefferson University Hospital, Philadelphia, PA, USA \\ ${ }^{2}$ Department of Internal Medicine, Thomas Jefferson University Hospital, Philadelphia, PA, USA
}

\begin{abstract}
Aim: To assess whether implementation of the care coordination program reduces 30 -day readmissions, and identify characteristics that increase susceptibility to readmission.

Methods: Our institution is an urban quaternary care liver transplant center performing approximately 50 liver transplants yearly in highly competitive UNOS Region 2. Our care coordination program focuses on patient education, short-term outpatient follow-up visits, and post-discharge follow-up calls by a transplant coordinator. During inpatient admission, patients deemed high-risk by attending hepatologists were enrolled. A retrospective chart review was conducted for all patients enrolled in care coordination from September 2014-April 2015. Basic demographic information, including age, gender, and ethnicity was collected. In addition, model for end-stage liver disease (MELD) score on index admission, as well as type of cirrhosis decompensation was recorded.

Results: A total of 69 patients deemed high-risk for readmission were enrolled in the CC program. Of these patients, 30-day readmissions occured in 46.3\%. There was no significant difference between MELD score on index admission for those readmitted within 30 days, and those who were not. Patients that were readmitted twice within a 30 day period, however, had an average MELD on index admission higher than those not readmitted within 30 days, with trend toward significance (24.3 vs. 19.1, p=0.07). Hepatic encephalopathy was the There were no differences between cirrhosis etiology, race, or type of decompensations between groups. A total of 15 post-transplant patients were included. Of those post-transplant patients who were readmitted within 30 days, the majority of them had recurrent HCV cirrhosis.
\end{abstract}

Conclusion: Higher MELD scores portend increased chance of readmission, with encephalopathy being the most common reason for readmission.

\section{Introduction}

With the increasing financial pressures faced by hospitals, readmission rates have taken the forefront as a quality metric for patient care [1]. All subspecialties have been affected by frequent readmissions, especially cardiology and pulmonary, as heart and lung disease have been deemed risk factors for readmission [2]. Moreover, studies have looked at numerous interventions aimed reducing readmission rates, and it was found that interventions that involved more individuals in delivery of care, and those that supported the patient's ability for selfcare were the most effective in reducing early readmission rates within 30 days of discharge [3]. The transition of care from the hospital to the home upon discharge has been another area of focus. Regalbuto et al. [4] showed that in heart failure patients being discharged from the hospital, only $10 \%$ understood all of their discharge instructions, potentially increasing the likelihood of readmission.

In addition to the heart failure and pneumonia patients most commonly implicated in hospital readmissions, there has been a recent shift towards looking at readmission rates in those with end stage liver disease (ESLD). Specifically, Volk et al. [5] studied 402 patients who were admitted for a complication of cirrhosis (ascites, spontaneous bacterial peritonitis, renal failure, hepatic encephalopathy, or variceal hemorrhage), and found that $37 \%$ of patients were readmitted within one month of discharge, a higher rate than seen in those with Medicare, and in heart failure patients. Moreover, each of these readmissions cost upwards of $\$ 20,000$. Readmissions among patients with cirrhosis are only increasing the monetary burden that ESLD creates.
The aim of this study is to determine whether the creation of a care coordination program will decrease 30 -day readmission rates in our ESLD population. The main elements of the program focuses on patient education, appointment scheduling, post-discharge follow-up phone calls, and patient transition to the outpatient hepatology practice.

\section{Methods}

During inpatient admission, high risk patients were idenitified based on the following criteria: recurrent encephalopathy, refractory ascites with frequent need for paracentesis, advanced cirrhosis with failure to thrive, and/or poor social support, per the disgression of the attending physician. Once patients were identified, an order would be placed in the electronic ordering system, which involves notification of the inpatient transplant coordinator, pharmacist, and case manager. Patients were set up with oupatient hepatology appointments within one week of discharge, and would receive follow-up phones calls from the transplant coordinator 48 hours after discharge, then at day 7, 14, 21, and 30.

Correspondence to: Dina Halegoua-DeMarzio, Assistant Professor, Division of Gastroenterology and Hepatology, Thomas Jefferson University Hospital, Philadelphia, PA, Tel: 215-955-8900; Fax: 215-503-2146; E-mail: Dina.Halegoua-DeMarzio@jefferson.edu

Key words: readmission rates; end-stage liver disease; hospital-based initiative; hepatic encephalopathy; model for end stage liver disease (MELD) score

Received: July 07, 2016; Accepted: August 15, 2016; Published: August 18, 2016 
A retrospective chart review was conducted for all patients enrolled in the care coordination program from September 2014-April 2015. Basic demographic information, including age, gender, and ethnicity was collected. In addition, model for end-stage liver disease (MELD) score on index admission, as well as cirrhosis etiology, and type of decompensation was recorded. Reason for index admission, as well as reason for readmission, if applicable, was noted. Any patients with repeated enrollment in care coordination during this time period were excluded. Statistical analyis using t-tests or chi-squared testing, where appropriate, was used to analyze the results.

\section{Results}

A total of 69 patients deemed high-risk for readmission were enrolled in the care coordination program between September 2014 and April 2015. Of these patients, 30-day readmissions occured in $46.3 \%$. Demographic information and characteristics between each group are detailed in Table 1. Hepatitis C virus (HCV) and alcohol related cirrhosis were the two most common etiologies of liver disease in both groups. There was no statistical significance between etiologies of cirrhosis and readmission $(p=0.29)$. There was no difference in race between those readmitted within 30 days and those who were not, with Caucasians being the most common in both groups. Age between both groups, as well as insurance types were also similar. Types of decompensations varied between both groups, with ascites and/or spontaneous bacterial peritonitis, esophageal varices, and hepatic encephalopathy being the most common. The presence of hepatocellular carcinoma also did not increase the likelihood of 30 day readmission.

Of those patients readmitted within 30 days of discharge, average MELD on index presentation was 20.36, with a median of 20 (range 7-38). This compares with those patients who were not readmitted within 30 days who had average MELD on index presentation of 19.1, with a median of 18 (range 9-37), p value 0.24 (Table 2). Reasons for readmission varied, including everything from abdominal pain to hepatic encephalopathy, which was the most common reason for readmission.

Six patients were readmitted twice during the 30-day period after discharge. These patient had an average MELD on index admission of 24.3, with a median MELD score of 22 (range 19-38). When compared with MELD scores on index admission for patients who were not readmitted within 30 days, this value approached statistical significance $(\mathrm{p}=0.07)$.

Of the 69 patients enrolled in the care coordination program, 15 patients were post-transplant, with 8 of the post-transplant patients being in the group that was readmitted within 30 days, as compared with 7 in the group that was not readmitted (Table 3). Of those readmitted, $5 / 8$ patients had recurrent $\mathrm{HCV}$ cirrhosis, with initial date of transplant ranging from 2007-2013. In those who were not readmitted, 2 out of the 7 transplanted patients had recurrent HCV cirrhosis, with initial date of transplant ranging from 2006-2012.

Table 1. Characteristics between those readmitted within 30 days and those who were not readmitted.

\begin{tabular}{|c|c|c|c|}
\hline & 30-day readmission $(n=32)$ & Not readmitted $(n=37)$ & \\
\hline Gender & $\begin{array}{l}\text { Male (17) } \\
\text { Female (15) }\end{array}$ & $\begin{array}{l}\text { Male (23) } \\
\text { Female (14) }\end{array}$ & $\mathrm{P}=0.45$ \\
\hline Race & $\begin{array}{l}\text { Caucasian (24) } \\
\text { African American (5) } \\
\text { Hispanic (3) }\end{array}$ & $\begin{array}{l}\text { Caucasian (27) } \\
\text { African American (8) } \\
\text { Hispanic (2) }\end{array}$ & $\mathrm{P}=0.70$ \\
\hline Average Age & 57 & 58 & $\mathrm{P}=0.86$ \\
\hline Etiology of cirrhosis & $\begin{array}{l}\text { HCV (14) } \\
\text { Alcohol (7) } \\
\text { HCV/Etoh (4) } \\
\text { NASH (3) } \\
\text { AIH (1) } \\
\text { Other (3) }\end{array}$ & $\begin{array}{l}\text { HCV (11) } \\
\text { Alcohol (11) } \\
\text { HCV/Etoh (1) } \\
\text { NASH (3) } \\
\text { AIH (4) } \\
\text { Other (7) }\end{array}$ & $\mathrm{P}=0.29$ \\
\hline Average MELD on index admission & 20.36 & 19.1 & $\mathrm{P}=0.24$ \\
\hline Insurance Type & $\begin{array}{l}\text { Medicare (10) } \\
\text { Private (17) } \\
\text { Medicaid (5) }\end{array}$ & $\begin{array}{l}\text { Medicare (14) } \\
\text { Private (16) } \\
\text { Medicaid (7) }\end{array}$ & $\mathrm{P}=0.71$ \\
\hline Decompensations & $\begin{array}{l}\text { Ascites/SBP (14) } \\
\text { Esophageal varices (16) } \\
\text { Hepatic encephalopathy (11) } \\
\text { Hepatic hydrothorax (4) } \\
\text { Hepatocellular carcinoma (4) } \\
\text { Hepatorenal syndrome (1) }\end{array}$ & $\begin{array}{l}\text { Ascites/SBP (21) } \\
\text { Esophageal varices (10) } \\
\text { Hepatic encephalopathy (15) } \\
\text { Hepatic hydrothorax (2) } \\
\text { Hepatocellular carcinoma (6) } \\
\text { Hepatorenal syndrome (5) }\end{array}$ & \\
\hline
\end{tabular}

Table 2. Index MELD scores between those readmitted within 30 days, those not readmitted in 30 days, and those with multiple readmissions within 30 days.

\begin{tabular}{|l|c|c|c|}
\hline & $\begin{array}{c}\text { 30 day readmission } \\
(\mathbf{n = 3 2})\end{array}$ & $\begin{array}{c}\text { Not readmitted } \\
(\mathbf{n = 3 7 )}\end{array}$ & $\begin{array}{c}\text { Multiple readmissions within 30 days } \\
(\mathbf{n}=\mathbf{6})\end{array}$ \\
\hline Average index MELD & 20.36 & 19.1 & 24.3 \\
\hline Median index MELD & 20 & 18 & 22 \\
\hline
\end{tabular}

Table 3. Post-transplant patients enrolled in care coordination.

\begin{tabular}{|c|c|c|}
\hline & $\begin{array}{c}\text { 30-day readmission } \\
(\mathrm{n}=8)\end{array}$ & $\begin{array}{c}\text { Not readmitted } \\
(n=7)\end{array}$ \\
\hline Reason for transplant & $\begin{array}{c}\text { HCV (4) } \\
\text { Etoh/HCV (2) } \\
\text { Other (2) }\end{array}$ & $\begin{array}{l}\text { HCV (4) } \\
\text { Etoh (2) } \\
\text { AIH (1) }\end{array}$ \\
\hline Recurrent HCV cirrhosis & $5 / 8$ & $3 / 7$ \\
\hline
\end{tabular}




\section{Discussion}

With the continued scarcity of donor organs, patients in need of liver transplant are often forced to wait until they are on death's doorstep before eligible for a new liver, as highlighted by the high MELD scores on transplantation in certain regions [6]. As patients continue to get sicker, it can be argued that their need for hospitalization becomes more frequent. Our care coordination program is meant to target these patients with frequent hospitalization needs and provide a more structured support in the outpatient setting to prevent unnecessary readmissions to the hospital.

In our cohort of patients enrolled in the care coordination program, there was no statistically significant difference in MELD score between those who were readmitted within 30 days of discharge and those who were not. However, those who had multiple readmissions within 30 days were more likely to have a higher MELD score on index admission as compared to those not readmitted within 30 days, with a trend toward significance. Perhaps this finding reflects the notion that those with higher MELD scores are more likely to struggle after discharge from the hospital, and thus should be the target of any initiative aimed at reducing readmissions.

Hepatic encephalopathy was the most common reason for readmission in our patient population. This has also been seen in other studies, specifically Tapper et al. [7] where it was noted that encephalopathy was most strongly associated with readmission within 30 and 90 days. In addition to those with higher MELD scores, perhaps targeting patients with hepatic encephalopathy would be a prudent approach at decreasing readmission rates in those with ESLD.

While our study includes both patients who are pre and post liver transplantation, a recent prospective trial studied readmission rates in the post-liver transplant population. Russo et al. [8] designed a protocol that focused on expansion of outpatient services, enhacement of discharge planning and teaching, and increasing use of observation status for short inpatient admissions, with the aim to decrease the readmission rates after liver transplantion. With initiation of this protocol, post-transplantation readimssion rates were decreased from $40 \%$ to $20 \%$.

Although the number of post-transplant patients were limited in our cohort, some interesting observations can still be drawn from our data. In total, 15 patients enrolled in the care coordination study were post-transplantation. More than half of these patients had $\mathrm{HCV}$ related or $\mathrm{HCV} / \mathrm{alcohol}$ related cirrhosis. The majority of these patients ultimately developed recurrent HCV infection and subsequent cirrhosis. While the authors recognize that this a small sample size, perhaps we can extrapolate that at least some of the burden of ESLD readmissions is due to recurrent HCV cirrhosis in patients who have been transplanted. With the advent of numerous direct acting antivirals that have been approved in the post-transplant population [9], it is possible that eradication of $\mathrm{HCV}$ will ultimately prevent a fair number of readmissions. In addition, most of the published data on readmissions in the ESLD population are from a few years ago, and now that treatment of $\mathrm{HCV}$ post-transplant is much more commonplace, perhaps a more current study would be beneficial to see if the overall rates of readmission are reduced in the setting of aggressive $\mathrm{HCV}$ treatment post liver transplantation.

Being a retrospective chart review, there are numerous limitations to this study. First of all, our sample size is quite small, making it challenging to see any statistically significant findings. Patients who were enrolled in the care coordination program mutiple times during the study period were excluded, also limiting the number in our sample size. Tapper et al. has showed that almost $25 \%$ of readmissions in cirrhotics were to a different hospital than from which the patient was initially discharged. That being said, though our transplant center does a thorough job of following patients after discharge, there certainly may have been readmissions to outside hospitals that were missed.

\section{Conclusion}

Those with higher MELD scores and those with hepatic encephlaopathy are perhaps more likely to have frequent readmissions, and should be the target of initiatives aimed at preventing rehospitalization. More studies need to be conducted in order to assess the impact of treatment of HCV in post-transplant patients on the rates of readmission in patients with ESLD.

\section{Author contributions}

Sheela S. Reddy designed the protocol, participated in data collection, and wrote the manuscript. Amy Javia performed data collection. Dina Halegoua-DeMarzio designed the protocol, and contributed the the writing of the manuscript and its critical review.

\section{Institutional review board statement}

This study was reviewed and approved by the Thomas Jefferson University Hospital Institutional Review Board.

\section{Conflict of interest statement}

None of the authors have any conflicts of interest to disclose.

\section{Data sharing statement}

No additional data are available.

\section{References}

1. Friedman B, Basu J (2004) The rate and cost of hospital readmissions for preventable conditions. Med Care Res Rev 61: 225-240. [Crossref]

2. Balaban RB, Galbraith AA, Burns ME, Vialle-Valentin CE, Larochelle MR, et al (2015) A patient navigator intervention to reduce hospital readmissions among highrisk safety-net patients: a randomized controlled trial. J Gen Intern Med. 30: 907-915. [Crossref]

3. Leppin AL, Gionfriddo MR, Kessler M, Brito JP, Mair FS, et al. (2014) Preventing 30day hospital readmissions: a systematic review and meta-analysis of randomized trials. JAMA Intern Med. 174: 1095-1107. [Crossref]

4. Regalbuto R, Maurer MS, Chapel D, Mendez J, Shaffer JA (2014) Joint Commission requirements for discharge instructions in patients with heart failure: is understanding important for preventing readmissions? J Card Fail 20: 641-649. [Crossref]

5. Volk ML, Tocco RS, Bazick J, Rakoski MO, Lok AS (2012) Hospital readmissions among patients with decompensated cirrhosis. Am J Gastroenterol 107: 247-252. [Crossref]

6. Nekrasov V, Matsuoka L, Rauf M, Kaur N, Cao S, et al. (2016) National Outcomes of Liver Transplantation for MELD $\geq 40$ : The Impact of Share 35. Am J Transplant [Crossref]

7. Tapper EB, Halbert B, Mellinger J (2016) Rates of and reasons for hospital readmissions in patients with cirrhosis: A multistate population-based cohort study Clin Gastroenterol Hepatol 14: 1181-1188 [Crossref] 
8. Russo MW, Levi DM, Pierce R, Casingal V, Eskin L, et al. (2016) A prospective study of a protocol that reduces readmission after liver transplantation. Liver Transpl 22: 765-772. [Crossref]
9. Jothimani D, Govil S, Rela M (2016) Management of post liver transplantation recurrent hepatitis $\mathrm{C}$

10. infection with directly acting antiviral drugs: a review. Hepatol Int. [Crossref]

Copyright: (2016 Reddy SS. This is an open-access article distributed under the terms of the Creative Commons Attribution License, which permits unrestricted use, distribution, and reproduction in any medium, provided the original author and source are credited. 